\title{
DEVELOPMENT OF IT COMPETENCE OF MASTER STUDENTS OF PEDAGOGICAL EDUCATION IN THE CONTEXT OF THE PEDAGOGICAL UNIVERSITY ELECTRONIC EDUCATIONAL SPACE DEVELOPMENT
}

(C) 2017

Dobudko Tatyana Valeryanovna, doctor of pedagogical sciences, professor, head of Computer Science, Applied Mathematics and Teaching Methods Department Pugach Valeriy Isaakovich, doctor of pedagogical sciences, professor of Computer Science, Applied Mathematics and Teaching Methods Department

Burtsev Nikolay Pavlovich, candidate of pedagogical sciences,

associate professor of Computer Science, Applied Mathematics and Teaching Methods Department Pugach Olga Isaakovna, candidate of pedagogical sciences, associate professor of Computer Science, Applied Mathematics and Teaching Methods Department Tyuzhina Irina Viktorovna, candidate of pedagogical sciences, associate professor of Computer Science, Applied Mathematics and Teaching Methods Department Danilyukov Pavel Anatolyevich, assistant of Computer Science, Applied Mathematics and Teaching Methods Department

Samara State University of Social Sciences and Education (Samara, Russian Federation)

Abstract. A two-level education system «bachelor-master», designed to ensure transparency, academic mobility, competitiveness and integration with the European institutions acts as a subject of social and pedagogical discourses on a wide range of issues to this day. The paper discusses the issue of training of masters majoring in pedagogical education, the development of general and professional competencies, and readiness for pedagogical activities. The authors note the key role of IT competence of graduates, linking it with the continuous processes of education informatization, development of the electronic educational space of pedagogical universities. It is also noted that the development of IT competence of masters of pedagogical education is one of the most important conditions for «leveling» students and ensuring a personal experience with electronic educational space of the university. IT competence consists of electronic (mainly remote) education; digital learning resources; software e-learning system; virtual processes and resources of educational activities; technical means that generate electronic space. The authors propose to develop the basic level of the competence within the discipline «Information technologies» using a set of specially selected competence-oriented tasks. The assumptions made by the authors were reflected during educational practice which is also described in this paper.

Keywords: electronic educational space; information technology competence; Bologna process; master's degree; teacher education; training of masters majoring in Pedagogy; information technology; legal-reference system; digital libraries; abstracting; pedagogical experiment; processing results of pedagogical experiment; control and measuring materials.

УДК 378

\section{ГОТОВНОСТЬ КУРСАНТОВ ВЕДОМСТВЕННОГО ВУЗА ФСИН К РАБОТЕ С ОСУЖДЁННЫМИ (ТЕОРЕТИЧЕСКИЙ АСПЕКТ)}

(C) 2017

Жирякова Евгения Анатольевна, преподаватель кафедры уголовного и уголовно-исполнительного права Самарский юридический институт Федеральной службы исполнения наказаний

(2. Самара, Российская Федерация)

Аннотация. Потребность в высококвалифицированных специалистах, способных незамедлительно и компетентно принимать эффективные решения в целях решения поставленных задач, обусловила повышение требований к системе ведомственного высшего профессионального образования, осуществляющей подготовку кадров для учреждений и органов уголовно-исполнительной системы (УИС). Эффективность функционирования исправительных учреждений УИС зависит от сформированности у выпускаемого специалиста готовности к работе с осуждёнными. Невзирая на то, что понятие «готовность» было введено в научный оборот в 50-60 гг. XX века Б.Г. Ананьевым, за всё время исследования этой категории в педагогической науке так и не было выработано единообразия в его понимании. Полярность во взглядах большинства учёных наполняет его смысл различным содержанием, которое зависит от выбранного исследователем подхода к пониманию сущности готовности к профессиональной деятельности. В статье характеризуются функциональный, психологический, личностный, интегративный подходы.

Содержание готовности к профессиональной деятельности определяется требованиями, которые предъявляет деятельность к личности специалиста. Деятельность сотрудников УИС обладает специфическими особенностями, главными из которых являются направленность на осуждённых, её правовой, властный, жёстко субординированный характер. Готовность к работе с осуждёнными понимается нами как интегративный синтез когнитивного, деятельностного и личностного компонентов, позволяющий успешно осуществлять профессиональную деятельность, обеспечивающий её наибольшую продуктивность. 
Ключевые слова: готовность; готовность к профессиональной деятельности; подходы к пониманию сущности готовности; компетентность и готовность; специфические особенности профессиональной деятельности сотрудника УИС; структура готовности курсанта к работе с осуждёнными.

На сегодняшний день, с учётом сложной и нестабильной социально-экономической обстановки в стране, назрела острая потребность в высококвалифицированных специалистах, способных незамедлительно и компетентно принимать эффективные меры в целях решения поставленных задач. Подготовка таких специалистов возлагается на образовательные учреждения высшего образования, к числу которых относятся и ведомственные вузы уголовно-исполнительной системы (УИС).

Система ведомственного высшего профессионального образования осуществляет подготовку кадров для учреждений и органов УИС, специфика деятельности которых предъявляет достаточно высокие требования как к личным, так и к деловым качествам сотрудника. Достаточно сказать, что сотрудникам УИС приходится ежедневно сталкиваться с психологическим, а в некоторых случаях и с физическим риском, поскольку пенитенциарная преступность (преступность в местах лишения свободы) находится на весьма высоком уровне.

Снижение уровня пенитенциарной и постпенитенциарной преступности, достижение цели наказания - исправление осуждённого - во многом зависит от эффективности деятельности персонала, от качества выполнения им профессиональных и служебных обязанностей, в связи с чем основной задачей системы ведомственной подготовки кадров для УИС является формирование готовности выпускаемого специалиста к профессиональной деятельности.

Термин «готовность» как научное понятие был введён в 50-60 гг. ХХ века Б.Г. Ананьевым. Немалый срок его существования и разработки в психолого-педагогической науке находит своё воплощение в самых различных, порой противоположных смыслах, которые вкладывают учёные в его содержание. В самом общем виде под готовностью понимается либо наличие у человека знаний, умений и навыков, необходимых для успешного выполнения деятельности, либо согласие и решимость совершить определённые действия в ответ на предъявленный стимул (сигнал): это - «состояние мобилизации всех психофизиологических систем человека, обеспечивающих эффективное выполнение определённых действий» [1], это - «психическое состояние, которое характеризуется мобилизацией ресурсов субъектов труда на оперативное или долгосрочное выполнение конкретной деятельности или трудовой задачи» [2; 3], что требует высокого уровня сформированности различных компонентов готовности, физическую подготовленность человека, а также необходимую нейродинамическую обеспеченность действий. Б.Г. Ананьев разделял готовность на общую и специальную; Б.Ф. Пуни, В.А. Сластенин выделяют функциональную и личностную готовность; Л.С. Нерсесян и В.Н. Пушкин - временную (ситуативную) и долговременную (устойчивую) готовность; Р.А. Низманов - моральную и профессиональную; Ю.К. Васильев, Ф.Н. Гоноболин, Ю.К. Некрасов, А.И. Щербаков психологическую и практическую готовность.

Определённое направление для анализа категории «готовность» дают сложившиеся с течением времени подходы: функциональный, психологический, личностный, интегративный.

Функциональный подход основывается на взглядах С.Л. Рубинштейна [4] и сводит готовность к деятельности к готовности (сформированности) психических функций выполнять те или иные действия, поскольку именно сформированность психических функций является необходимым условием успешности и эффективности любой деятельности человека. Представители этого подхода считают, что готовность к осуществлению какой-либо деятельности есть особенное психическое состояние личности, служащее фоном для психических процессов (восприятия, воображения, мышления, памяти).

Функциональный подход является основой психологического подхода, который акцентирует внимание на развитии психических познавательных процессов, на формировании знаний, умений и навыков, являющихся наиболее важными для эффективного осуществления деятельности.

Личностный подход отражён в позиции таких учёных, как М.И. Дьяченко и Л.А. Кандыбович [5] и позволяет анализировать готовность к деятельности на личностном уровне, т.е. исследовать совокупность личностных качеств специалиста, которые обеспечивают выполнение им функций, адекватных требованиям деятельности. При этом содержание готовности может включать следующие аспекты:

1) готовность как комплекс способностей личности (С.Л. Рубинштейн и др.);

2) готовность как устойчивое свойство личности (А.Г. Ковалев [6] и др.) в совокупности нравственных и профессиональных компонентов;

3) готовность как состояние личности, при этом под психическим состоянием готовности понимается внутренняя установка, приспособление возможностей личности для продуктивных действий в данный момент времени в заданной ситуации. Человек предвидит ситуацию и готов, то есть настроен, мобилизован на преодоление возникающих трудностей и достижение положительного результата.

Интегративный подход отвечает научным реалиям современности, позволяет «видеть мир целостно, нерасчленённо», «достичь синергетического эффекта ... в противовес обособлению и дифференциации» [7, с. 77]. В аспекте рассматриваемой проблемы интегративный подход даёт возможность синтезировать все остальные рассмотренные подходы в одном, тем самым включив в «готовность» и знания, умения, навыки в соответствующей профессии [8], и способности личности, и общие психологические условия (интересы, склонности, психические состояния) [9], и её характерологические качества.

Интегративный подход разрешает выделить несколько функций готовности к профессиональной деятельности, важнейшими из которых являются гностическая, интегративная, прогностическая, ценностно-ориентировочная [10]. Гностическая функция тождественна познавательной направленности личности и проявляется в способности усваивать и применять знания в процессе осуществления професси- 
ональной деятельности, в стремлении к приобретению новых знаний и постоянному профессиональному росту, склонности к творческой самореализации личности.

Интегративная функция готовности к профессиональной деятельности проистекает из гностической и направлена на обобщение знаний, овладение системой общенаучных методов познавательной деятельности, их экстраполирования в сферу профессиональной деятельности. Реализация в личностном опыте этой функции разрешает подниматься до высот целостного, системного мышления, формировать критическое восприятие жизненных явлений, самостоятельно осуществлять поиск истины в условиях фактологической недостаточности.

Прогностическая функция заключается в способности предвидеть результаты профессиональной деятельности, оценивать и определять наиболее эффективные условия и способы действий, планировать волевые, мотивационные и интеллектуальные усилия с целью вероятности достижения результата. Следовательно, проектируя все элементы профессиональной деятельности, специалист берёт на себя ответственность за процесс и результат деятельности, самостоятельно и эффективно решает производственные проблемы.

Ценностно-ориентировочная функция отражает ценностные ориентации личности в области значимости профессии, к себе лично как к субъекту профессиональной деятельности. Соответственно, эта функция выражается в устойчивом интересе к своей профессии, в понимании её необходимости и нужности, в осмыслении своего места в профессиональной сфере.

Следовательно, готовность к деятельности - это интегративное качество личности, представляющее собой совокупность самых различных характеристик человека, что находит своё отражение в самых разнообразных определениях готовности. Приведём некоторые из них. Так, О.В. Царькова [11] определяет готовность как интегральное качество личности, которое характеризуется определённым уровнем её развития и обусловливает возможность личности участвовать в каком-либо процессе.

Л.Г. Семушина [12] понимает готовность к деятельности как психическое состояние человека, которое предполагает осознание человеком своих профессиональных целей, способность осуществлять анализ и оценку имеющихся условий, определять наиболее вероятные способы действия, предвидеть мотивационные, волевые и интеллектуальные усилия, вероятность достижения результатов.

С.А. Бондаренко [13] даёт определение профессиональной готовности как сложному психологопедагогическому явлению, сочетающему взаимосвязанные психологические особенности и нравственные качества личности, социально-ценностные мотивы выбора профессии, способы поведения, специальные профессиональные знания, умения и навыки, обеспечивающие специалисту возможность трудиться в избранной им профессиональной сфере.

В.Н. Михалин [14], изучая готовность к профессиональной деятельности курсантов вузов МЧС России, понимает её как интегративное личностное качество, включающее систему знаний, умений, навыков по специальным дисциплинам, профессионально значимые личностные качества, целенаправленное использование профессионального опыта во всех сферах его практической деятельности.

Общим признаком для всех этих определений является понимание готовности к деятельности как некоего многоаспектного, многокомпонентного интегративного феномена, состоящего из совокупности различных компонентов. Почему столь значительно расхождение взглядов исследователей на то, какие элементы наполняют содержание понятия «готовность к деятельности»? Очевидно, это обусловлено спецификой самой деятельности, к которой должен быть готов специалист. Чем более все компоненты готовности личности соответствуют требованиям деятельности, тем выше эффективность этой деятельности, тем более профессиональным и компетентным является специалист, её осуществляющий. В связи с этим для выделения наиболее существенных компонентов готовности сотрудников УИС к работе с осуждёнными необходимо, во-первых, в научном плане развести понятия «компетентность» и «готовность» и, во-вторых, проанализировать требования профессиональной деятельности сотрудника УИС.

Исследуя понятие «профессиональная готовность» и «профессиональная компетентность», большинство учёных сходятся во мнении о том, что это достаточно близкие понятия. Ряд исследователей практически отождествляет их: «определение выпускника, владеющего тем, что он может сделать, каким способом деятельности овладел, к чему готов и есть компетентность» $[15$, с. 52]. Схожее мнение высказывает и М.М. Шалашова: «Под компетентностью мы понимаем интегральное качество личности, характеризующее её готовность решать проблемы, возникающие в процессе жизни и профессиональной деятельности» [16, с. 54-59].

Но в то же время эти два понятия имеют и некоторое отличие, связанное с тем, что в понятии «готовность» акцентируется именно деятельностная составляющая: даже хорошо подготовленный к решению профессиональных задач специалист (компетентный специалист) в нужный момент может оказаться не мобилизован, не настроен на соответствующую деятельность, его психическая регуляция профессионального поведения и деятельности соответствующим образом может быть не актуализирована. В таком случае успешное осуществление деятельности будет невозможно либо она окажется малоэффективной. Взаимосвязь понятий «готовность к деятельности» и «компетентность» реализуется в том, что готовность специалиста к деятельности предполагает наличие у него соответствующего уровня профессиональной компетентности, профессионального мастерства, но подчёркивает высокий уровень развития саморегуляции, самонастроя, умений мобилизовать свой профессиональный (духовный, личностный и физический) потенциал на решение поставленных задач в соответствующих условиях.

В ведомственных вузах Федеральной службы исполнения наказаний готовят офицеров, которые после выпуска из института имеют необходимый уровень подготовки, позволяющий им служить в различных отделах пенитенциарных учреждений: в службе режима и безопасности, осуществлять оперативно-розыскную деятельность, работать начальни- 
ками отрядов и др. Объектом их профессиональной деятельности являются осуждённые, и учёт этого фактора - необходимое условие для понимания специфики служебной деятельности сотрудников уголовно-исполнительной системы.

Осуждённые - это люди, нарушившие закон, совершившие преступление и приговорённые судом к лишению свободы. Характеризуя социальную среду в пенитенциарных учреждениях, её часто называют криминальной, поскольку самой общей её характеристикой является низкий уровень образования и культуры осуждённых, искажение системы их ценностных ориентаций, наличие специфичной криминальной субкультуры и др. Как свидетельствуют исследования А.П. Деткова [17], социальная среда в местах лишения свободы весьма противоречива и неоднородна. Она характеризуется, прежде всего, разнообразием отбывающих наказание осуждённых не только по их уголовно-правовой и криминологической характеристике, но и с точки зрения их национальной, религиозной и половой принадлежности, семейного положения, возраста, образования и т.д. Асоциальная субкультура осуждённых является особым «генератором» деструктивных процессов, культивируя и усиливая противостояние в отношении установленного правового режима мест лишения свободы. Система ценностей неформальных норм (понятий), тюремных традиций, стратификация сообщества осуждённых, их деление на слои (страты), имеющие различное положение, права и обязанности в сфере неформального общения - вот неполный перечень характерных черт той среды, с которой сотрудники УИС находятся во взаимодействии большую часть времени. Это сказывается на их психическом здоровье, проявляется в профессиональной деформации [18].

Кроме этого, как указывают А.И. Ушатиков и Б.Б. Казак [19, с. 645], специфика деятельности сотрудника УИС выражена в её правовом, субординированном характере, в реализации властных полномочий и др.

Правовой характер деятельности сотрудника УИС находит своё выражение в строгой её регламентации правовыми нормами, содержащимися в уголовном и уголовно-исполнительном законодательстве, нормативно-правовых актах и других правовых документах, призванных строго регулировать законность при исполнении и отбывании уголовного наказания. Практически все основные сферы жизнедеятельности осуждённых (трудовая, производственная, общественная, учебная, бытовая и др.), а также все взаимоотношения между сотрудниками и осуждёнными подвергнуты правовому регулированию: каждое действие сотрудника, выходящее за рамки правовых норм, влечёт за собой серьёзные правовые последствия, вплоть до уголовного преследования. Именно эта особенность профессиональной деятель- ности сотрудника УИС делает её социально значимой и отличает от многих других профессий.

Чёткая субординация, выраженная в беспрекословном выполнении приказов вышестоящего начальства, также отличает профессиональную деятельность сотрудников УИС от многих других профессий. С одной стороны, это свидетельствует об авторитарности системы (авторитарный стиль имеет много недостатков, главным из которых является тотальный контроль и игнорирование индивидуальных особенностей личности), с другой - без этого пенитенциарная система не может существовать, так как от чёткости, организованности, согласованности действий её отдельных звеньев зависит эффективность всей деятельности.

Наличие властных полномочий у сотрудника УИС также является специфической особенностью профессиональной деятельности. Имея право на применение санкций, сотрудник исправительного учреждения уполномочен на принудительную силу власти, которую ему дало государство, поскольку именно государство осуществляет принудительное исполнение наказания в отношении лица, совершившего преступление. Умение пользоваться властью, то есть оставаться объективным в принятии решения, не включая в оценку ситуации ни сочувствия, ни возмущения, ни других эмоциональных качеств - специфическая черта профессиональной деятельности сотрудника УИС.

Таким образом, учитывая специфические особенности профессиональной деятельности сотрудников УИС, можно выделить основные компоненты готовности к работе с осуждёнными (табл. 1).

Таким образом, готовность к работе с осуждёнными - это сложносоставной комплекс психических процессов, состояний, личностных качеств человека. В рассматриваемую готовность с необходимостью входят знания из разных социальных сфер, поскольку без них невозможно быть компетентным специалистом: правовые знания, лежащие в основе взаимоотношений с осуждёнными и регулирующие все аспекты профессиональной жизнедеятельности; психолого-педагогические, так как исправление осуждённых, их ресоциализация и социальная адаптация - цель деятельности всей пенитенциарной системы осуществляются посредством воспитательной работы с осуждёнными; организационные, так как воспитательная работа реализовывается системой воспитательных мероприятий; служебные, связанные с возможностью применения спецсредств, оружия в случае возникновения экстремальных ситуаций, массовых эксцессов и др.

Таблица 1 - Основные компоненты готовности к работе с осуждёнными

\begin{tabular}{|c|c|c|}
\hline Когнитивный & Деятельностный & Личностный \\
\hline $\begin{array}{l}\text { Знания: } \\
\text { правовые, } \\
\text { психолого- } \\
\text { педагогические, } \\
\text { организационные, } \\
\text { служебные }\end{array}$ & $\begin{array}{l}\text { Умения и навыки } \\
\text { применять знания на практике; } \\
\text { владение способами, операци- } \\
\text { ями и приёмами деятельности, } \\
\text { опирающееся на знания }\end{array}$ & $\begin{array}{l}\text { Мотивация (желание работать и достигать результа- } \\
\text { тов в работе с осуждёнными); } \\
\text { нравственность (честность, антикоррупционная } \\
\text { направленность); } \\
\text { профессионально важные качества (стрессоустойчи- } \\
\text { вость, самоконтроль, воля) }\end{array}$ \\
\hline
\end{tabular}


Деятельностный компонент готовности к работе с осуждёнными образуют умения и навыки, понимаемые как автоматизированные в результате многократных повторений действия, и выработанные способы поведения личности, опирающиеся на знания.

Личностный компонент должен быть наполнен и мотивационно-ценностным отношением к профессии, пониманием её социальной значимости, и высоким уровнем развития нравственной сферы личности. Большое значение имеют особенности психических познавательных процессов, тип нервной деятельности, связанные с важнейшими сторонами профессии; эмоциональные и волевые компоненты, поскольку они могут как усиливать, так и ослаблять активность человека, способствовать или тормозить совершение эффективных действий по достижению цели. Готовность к работе с осуждёнными понимается нами как интегративный синтез когнитивного, деятельностного и личностного компонентов, позволяющий успешно осуществлять профессиональную деятельность, обеспечивающий её наибольшую продуктивность. Формирование всех компонентов готовности - задача первостепенной важности, которую реализуют ведомственные вузы уголовно-исполнительной системы РФ.

\section{СПИСОК ЛИТЕРАТУРЫ:}

1. Большой психологический словарь / общ. ред. В.П. Зинченко, Б.Г. Мещерякова. СПб.: ПРАЙМЕВРОЗНАК, 2003. $672 \mathrm{c}$.

2. Психология / под ред. В.Н. Дружинина. СПб., $2001.656 \mathrm{c}$.

3. Пиюкова С.С. Формирование психологической готовности сотрудников УИИ к работе с оборудованием СЭМПЛ // Назначение и исполнение наказаний, не связанных с лишением свободы, и иных мер уголовно-правового характера: мат-лы III всерос. науч.-практ. конф. (27 марта 2015 г.). Самара: Самарский юридический институт ФСИН России, 2015. С. $140-144$.

4. Рубинштейн С.Л. Основы общей психологии: в 2-х т. М., 1989. 486 c.

5. Дьяченко М.И., Кандыбович Л.А. Психология высшей школы. 3-е изд., перераб. и доп. Мн.: Университетское, 1993. 368 с.

6. Ковалев А.Г. Предмет и проблемы социальной психологии. Л., 1962. 287 с.

7. Ощепкова О.В., Благов Ю.В. Теоретические основы реализации интегративного подхода в образовательном процессе // Вестник Самарского государст- венного технического университета. Серия: Психолого-педагогические науки. № 3 (23). 2014. С. 164-169.

8. Мерлин В.С. Очерк интегрального исследования индивидуальности. М., 1986. 256 с.

9. Крутецкий В.А. Основы педагогической психологии. М.: Просвещение, 1972. 253 с.

10. Русаков Ю.Т. Развивающая образовательная среда колледжа как фактор формирования готовности студентов к профессиональной деятельности: автореф. дис. ... канд. пед. наук. Магнитогорск, 2006. $40 \mathrm{c}$.

11. Царькова О.В. Формирование готовности будущего техника к решению инновационных производственных задач: автореф. дис. ... канд. пед. наук. Оренбург, 2009. 36 с.

12. Семушина Л.Г. Разработка методики контроля готовности к профессиональной деятельности студентов вузов // Среднее профессиональное образование. 2003. № 10. С. 10-14.

13. Бондаренко С.А. Формирование профессиональной готовности конкурентоспособного специалиста // Модернизация высшей школы: обеспечение качества профессионального образования: мат-лы всерос. науч.-практ. конф. Барнаул: Изд-во ААЭП, 2004. Ч. $1.188 \mathrm{c}$.

14. Михалин В.Н. Сущность и основные компоненты готовности к профессиональной деятельности курсантов вузов МЧС России [Электронный ресурс] // Научный журнал КубГАУ. 2013. № 86 (02). http://ej.kubagro.ru/get.asp?id=2680.

15. Селевко Г.К. Современные образовательные технологии. М., Народное образование, 1998. 256 с.

16. Шалашова М.М. Комплексная оценка компетентности будущих педагогов // Педагогика. 2008. № 7. С. 54-59.

17. Детков А.П. Теоретические и методологические проблемы пенитенциарной конфликтологии: уголовно-правовые и уголовно-исполнительные аспекты. Екатеринбург: Уральская государственная юридическая академия, 2011. 356 с.

18. Ежова О.Н., Маслов В.В., Ощепкова О.В. Профилактика и коррекция профессиональной деформации сотрудников уголовно-исполнительной системы: учеб.-метод. пособие. Самара: Самар. юрид. ин-т ФСИН России, 2005. 138 с.

19. Ушатиков А.И., Казак Б.Б. Пенитенциарная психология: учеб. Рязань: Академия права и управления Минюста России, 2003. 758 с.

\title{
THE READINESS OF FPS OF RUSSIA DEPARTMENTAL INSTITUTE CADETS FOR WORK WITH THE CONVICTED (THEORETICAL ASPECT)
}

(C) 2017

\author{
Zhiryakova Evgeniya Anatolievna, lecturer of Penal Law Department \\ Samara Law Institute of the Federal Penitentiary Service of Russia (Samara, Russian Federation)
}

Abstract. The necessity of professionals who are able to take effective measures immediately and adequately for the purposes of achieving goals has conditioned the requirements increase to the system of the departmental higher professional education that trains personnel for the penal bodies (the Penal System). The effectiveness of the penal correctional facilities depends on the level of graduates' readiness for work with the convicted. The concept «readiness» was introduced into scientific use in 1950-1960 by B.G. Ananiev, but a unified position on its understanding has not been worked out in pedagogy. Scientists define it in different ways; it depends on the researcher approach to understanding the essence of readiness for professional activity. In this paper functional, psychological, personal, integrative approaches are characterized. 
The readiness for professional activity is determined by the requirements imposed to the specialist. The performance of the penal staff has some specific set of features; the main ones are focused on the convicted, as well as on its legal, peremptory, strictly subordinated character. The readiness for work with the convicted is thought of as an integrative synthesis of cognitive, personal components necessary for successful carrying out of professional activities and providing the greatest efficiency.

Keywords: readiness; readiness for professional activity; approaches to understanding essence of readiness; competence and readiness; specific features of professional activity of a penal officer; structure of cadet's readiness for work with convicted.

УДК 37.015.3:177

\section{МЕТОДИЧЕСКИЕ ОСНОВЫ ПРИМЕНЕНИЯ ТЕХНОЛОГИИ МОДУЛЬНОГО ОБУЧЕНИЯ ПРИ ИЗУЧЕНИИ ГРАММАТИКИ В НЕЯЗЫКОВЫХ ВУЗАХ} (C) 2017

Лопухова Юлия Викторовна, доктор педагогических наук,

профессор кафедры лингвистики, межкультурной коммуникации и русского языка как иностранного Самарский государственный технический университет (2. Самара, Российская Федераиия)

Аннотация. В статье обосновывается необходимость использования технологии модульного обучении при изучении грамматики в неязыковом вузе. При этом большое значение уделяется структуре модуля, которую необходимо организовать таким образом, чтобы конечный результат был ориентирован на индивидуальный успех. Это становится возможным, так как на входе применения технологии модульного обучении меняется форма общения преподавателя и студента. Обучение переводится на субъект-субъектную основу, поскольку технологии модульного обучении в качестве одной из основных целей преследует формирование у студентов навыков самообразования. Осознанность учебной деятельности переводит преподавателя из режима информирования в режим консультирования и управления. Преподаватель, освобождаясь от чисто информационных функций, делегирует модульной программе некоторые функции управления, которые становятся функциями самоуправления. Студент работает максимум времени самостоятельно, учится целеполаганию, самопланированию, самоорганизации, самоконтролю и самооценке. Содержание обучения представляется в законченных самостоятельных модулях, одновременно являющихся банком информации и методическим руководством по его применению. При осуществлении модульного обучения с позиции теории поэтапного формирования определенных навыков главную образовательную цель можно разделить на поэтапные задачи формирования навыка в рамках отдельных учебных элементов модуля.

Ключевые слова: технологии модульного обучении; модуль; самопланирование; самоорганизация; самоконтроль; самооценка; грамматический навык; учебный элемент; информационный блок; входной контроль; лист контроля; контроль.

В условиях обновления системы образования педагогу необходимо ориентироваться в широком спектре современных инновационных технологий, идей, направлений и не тратить время на открытие уже известного. Сегодня быть педагогически грамотным специалистом нельзя без изучения всего обширного арсенала образовательных технологий. Содержание образования необходимо обогащать новыми процессуальными аспектами, направленными на развитие у студентов способности быстро и качественно оперировать изменяющейся информацией, творчески и ответственно подходить к решению возникающих проблем. При этом основной акцент должен быть сделан на индивидуализации образовательных программ с целью активизации личностного потенциала каждого студента.

Обращение к проблемам использования технологии модульного обучении при изучении иностранного языка в вузе явилось результатом осознания возрастающей динамики инновационных процессов в обществе в целом. Многие исследователи отмечают, что технология модульного обучении в сравнении с традиционной технологией - более прогрессивная и плодотворная дидактическая технология, поскольку использует элементы в контексте педагогики сотрудничества. Она гуманизирует педагогический процесс и ведет к экономии времени обучения и затрат труда преподавателей.
Как показывает опыт работы, технология модульного обучения способна обеспечить целостный и системный подход к процессу изучения иностранного языка и создать благоприятные условия для развития личности обучаемого путем обеспечения гибкого содержания обучения, приспособления дидактической системы к индивидуальным возможностям, запросам и уровню базовой подготовки обучаемого посредством организации учебно-познавательной деятельности по индивидуальной учебной программе.

Говоря о практическом применении технологии модульного обучении, нам бы хотелось отметить тот факт, что данная технология успешно сочетается с традиционными методами обучения ИЯ $[1 ; 2]$. Мы использовали технологии модульного обучения при изучении грамматики ИЯ, что позволило модернизировать и оптимизировать учебный процесс, поскольку данная технология имеет ряд значительных преимуществ. Во-первых, содержание обучения представляется в законченных самостоятельных комплексах (информационных блоках), усвоение которых осуществляется в соответствии с целью и задачами обучения. Цель и задачи формируются для обучающегося и содержат в себе не только указание на объем изучаемого содержания, но и на уровень его усвоения. Кроме этого, каждый студент получает от преподавателя советы в письменной форме как рацио- 